\title{
Inhaled Corticosteroids and Bone Health
}

\author{
Carolyn Chee, ${ }^{*}$, Luckni Sellahewa ${ }^{2}$ and Joseph M. Pappachan ${ }^{3}$ \\ ${ }^{I}$ Department of Endocrinology, Nottingham University Hospitals, NG7 2UH, UK \\ ${ }^{2}$ Department of Endocrinology, Royal Derby Hospital, Derby, DE22 3NE, UK \\ ${ }^{3}$ Department of Endocrinology, Walsall Manor Hospital, West Midlands, WS2 9PS, UK
}

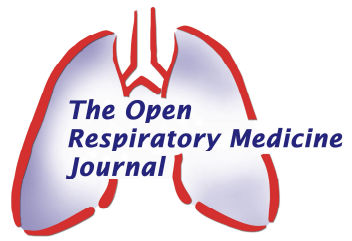

\begin{abstract}
Inhaled corticosteroids (ICS) are the cornerstones in the management of bronchial asthma and some cases of chronic obstructive pulmonary disease. Although ICS are claimed to have low side effect profiles, at high doses they can cause systemic adverse effects including bone diseases such as osteopenia, osteoporosis and osteonecrosis. Corticosteroids have detrimental effects on function and survival of osteoblasts and osteocytes, and with the prolongation of osteoclast survival, induce metabolic bone disease. Glucocorticoid-induced osteoporosis (GIO) can be associated with major complications such as vertebral and neck of femur fractures. The American College of Rheumatology (ACR) published criteria in 2010 for the management of GIO. ACR recommends bisphosphonates along with calcium and vitamin D supplements as the first-line agents for GIO management. ACR recommendations can be applied to manage patients on ICS with a high risk of developing metabolic bone disease. This review outlines the mechanisms and management of ICS-induced bone disease.
\end{abstract}

Keywords: Bisphosphonate, bone mineral density (BMD), glucocorticoid-induced osteoporosis (GIO), ICS-induced bone disease, inhaled corticosteroids (ICS).

\section{INTRODUCTION}

Inhaled corticosteroids (ICS) have been used for the long-term management of asthma and chronic obstructive pulmonary disease (COPD) over the past few decades. ICS are claimed to predominantly exert local effects in the airways with minimal systemic side effects, compared to enteral or parenteral steroids, making them the therapeutic agents of choice for the control of these chronic respiratory illnesses. Although systemic side effects are few with ICS, they do occur in a significant number of patients when used in high doses [1].

The reported systemic adverse effects related to chronic use of ICS include suppression of the hypothalamo-pituitaryadrenal axis, cataracts, thinning and bruising of the skin, adrenal insufficiency, growth retardation in children, Cushing syndrome and osteoporosis $[1,2]$. The incidence of systemic effects varies with the type of ICS used. The commonly used ICS are beclomethasone dipropionate (BDP), budesonide (BUD), fluticasone propionate (FP), Flunisolide (FLU), mometasone furoate (MF), and ciclesonide (CIC). The effects of ICS on bone health have given rise to much attention in recent years, particularly with the increasing prevalence of aged population worldwide, as poor bone health and its complications are strongly associated with reduced quality of life. This review outlines the effects of ICS on bone health and therapeutic strategies.

*Address correspondence to this author at the Department of Endocrinology, Nottingham University Hospitals, Nottingham, NG7 2UH, UK; Tel: +44-115 924 9924; Fax: +44-115 9701080;

E-mail:carolyn.chee@nuh.nhs.uk

\section{BONE ANATOMY AND PHYSIOLOGY}

Bone tissue is composed of collagen, matrix proteins, calcium hydroxyapatite, and three types of cells: osteoclasts, osteoblasts and osteocytes. Osteoclasts are responsible for bone resorption, whilst osteoblasts form the bone. Osteocytes are the main cells involved in the bone remodelling process through regulation of the other two cell types by their stimulation or inhibition [3]. Osteocytes are capable of detecting microdamage in the bone tissues and initiating repair in the damaged region [4]. A number of cytokines and growth factors are involved in the regulation of these complex processes which enables normal bone physiology and anatomy to be maintained.

There exists a delicate balance between bone formation and bone resorption in a healthy individual, and anything that disturbs this balance results in abnormal bone structure and function. Bone loss that results from osteoclast overactivity causes osteopenia in the early stages, and in the later stages, osteoporosis. Similarly, abnormal osteoblast function results in decreased bone formation and consequently osteopenia or osteoporosis develops.

Osteoblasts originate from the bone marrow-derived mesenchymal stem cells and osteoclasts from the haemopoietic stem cells $[5,6]$. Osteoclast activation and differentiation are mediated through the receptor for activated nuclear factor kappa B (RANK), the receptor for activated nuclear factor kappa B ligand (RANKL) and osteoprotegerin (OPG). Osteoblasts produce RANKL that binds to the trans-membrane receptor RANK on the osteoclast precursors and activate them to differentiate into mature osteoclasts $[5,6]$. Osteoblasts also produce OPG, a 
soluble decoy receptor that blocks RANKL, and thereby decrease osteoclast activation. There is a good balance between these systems (RANK/RANKL/OPG systems) in a healthy individual, and anything that disturbs this balance, may result in abnormalities in the bone homeostasis. The system is also influenced by various cytokines such as interleukin 1 (IL-1), interleukin 6 (IL-6), interleukin 7 (IL-7) interferon gamma (IFN- $\gamma$ ) and tumour necrosis factor alpha $(\mathrm{TNF}-\alpha)$ [5-8], and different hormones and nutrient factors [6].

The bone-forming osteoblasts and bone-degrading osteoclasts constitute a functional unit that determines the integrity and the strength of normal skeletal tissues. Mature osteoblasts secrete the bone matrix that becomes mineralized under the influence of calcium, phosphate and vitamin D [6]. RANKL produced by osteoblasts results in activation of the osteoclasts by the mechanism described above, and therefore appropriate remodelling of the mineralised bone occurs through osteoclast-mediated bone resorption, thus maintaining normal physiology in a healthy individual.

\section{CORTICOSTEROIDS AND BONE PHYSIOLOGY}

Glucocorticoids cause a reduction of osteoblastogenesis, increase osteoblast apoptosis and reduce their ability for bone formation [9, 10]. Glucocorticoid administration has been demonstrated to switch the osteogenic potential of the bone marrow mesenchymal stem cells to adipogenic differentiation that causes reduction of osteoblastogenesis $[11,12]$. Increased production of reactive oxygen species induced by steroids leads to osteoblast apoptosis [13]. Studies in mouse models showed that activation of glucocorticoid receptors in osteoblasts resulted in a reduction of bone mass, trabecular thickness, osteoblast numbers and colony forming units [14]. Steroid-induced suppression of osteoblast-derived cytokines such as interleukin 11 was also found to impair osteoblast differentiation [14].

Glucocorticoids also suppress osteoclastogenesis [10, 14, 15]. The suppression of osteoclast formation may be mediated through the glucocorticoid receptors in the osteoblasts and osteoclasts [14, 15]. However, unlike in the case of osteoblasts, steroids do not cause osteoclast apoptosis and can prolong osteoclast survival. Steroids may also inhibit bone resorption efficiency of osteoclasts by interfering with their cytoskeleton formation in response to macrophage colony stimulating factor [15].

Osteocytes are also affected by corticosteroids. Apoptosis of the osteocytes by administration of corticosteroids in the mouse model was first demonstrated by Weinstein et al. in 1998 [9]. Nearly 15-20\% of apoptotic osteocytes were seen in the steroid treated mice. Increased osteocyte lacunar size and loss of mineral around the osteocytes have also been demonstrated in steroid treated animal models [16]. Xia et al. demonstrated more than $50 \%$ reduction of osteocyte numbers in steroid treated mice [17]. Increased osteocyte autophagy was proposed as a mechanism by which glucocorticoids induced osteocyte apoptosis. Reductions in the blood flow to the bone canalicular system, and the water content of bone tissues are the other adverse consequences of steroids in the skeletal system $[9,10]$. Steroids may also affect the production and signalling of various cytokines and growth factors that control normal bone physiology.

\section{PATHOPHYSIOLOGY OF STEROID-INDUCED BONE DISEASE}

Steroid-induced bone disease was first reported in the 1950 's soon after the introduction of glucocorticoids for treatment of systemic diseases $[18,19]$. Steroid treatment is the most common cause of secondary osteoporosis and iatrogenic metabolic bone disease $[10,20]$. The prevalence of low bone mineral density (BMD) can be as high as $15.8 \%$ among steroid users [21]. A rapid decline in BMD of $6-12 \%$ in the first year, followed by an annual decline of about 3\% has been observed in long-term steroid users [10, 22]. A 75\% higher fracture risk was observed during the first 3 months of continuous steroid therapy $[10,23]$.

Steroid-induced bone disease was found to be associated with fewer numbers of osteoblasts and higher prevalence of apoptotic osteocytes in histological studies [9, 24, 25]. Excess osteocyte apoptosis is associated with reductions in the vascular endothelial growth factor, angiogenesis, interstitial fluid and the strength of skeletal tissues [26]. The loss of bone strength related to steroid use occurs before the loss of BMD that is peculiar to steroid-induced bone disease [20]. Although glucocorticoids directly suppress osteoclastogenesis, the prolongation of osteoclast lifespan, in conjunction with a decrease in lifespan of the osteoblasts, result in significant bone loss in long-term steroid users.

Osteopenia is the stage of significant bone loss that results in low BMD, assessed by dual-energy $x$-ray absorptiometry (DEXA) scan showing $T$ scores between -1 and -2.5 . In children and young adults $Z$ scores are used (instead of $\mathrm{T}$ scores), and values $\leq-2$ is classed as osteopenia [27]. Chronic steroid use showed a dose-response pattern in bone strength - a cumulative prednisone exposure of greater than $11136 \mathrm{mg}$ was associated with low BMD (odds ratio 8.9, $\mathrm{P}<0.001)$ compared to the control group, after adjustments for other confounding factors [271. Continued exposure of steroid is expected to result in worsening bone loss leading to osteoporosis.

The World Health Organization (WHO) defines osteoporosis as a systemic skeletal disease characterized by low bone mass and micro-architectural deterioration of bone tissue, with a consequent increase in bone fragility and susceptibility to fractures. Osteoporosis or low BMD affects approximately 52 million people in the United States, and approximately one in five men experience an osteoporotic fracture in their lifetime [28]. Women are more prone for developing osteoporotic fractures, and up to $40 \%$ of postmenopausal women suffer such a fracture in their lifetime [29]. The most common sites involved are the vertebral bodies and neck of femur. Osteoporosis is diagnosed when the $\mathrm{T}$ score is $<-2.5$ in the DEXA scan.

Osteoporotic fractures are associated with significant mortality and morbidity in the sufferers, especially older individuals. The estimated annual cost related to osteoporotic fractures exceeds $\$ .18$ billion in the US [28]. Recent data from the United Kingdom shows that the one-year all-cause mortality compared to controls following a hip fracture is 3.5-fold and 2.4-fold higher in males and females 
respectively [30]. Chronic use of corticosteroid is commonly associated with secondary osteoporosis and fractures (often asymptomatic) and may occur in as many as $30-50 \%$ of patients receiving long-term steroid therapy [31]. Therefore, physicians who prescribe corticosteroids for long-term use should consider the healthcare implications related to osteoporosis.

Osteonecrosis is the other metabolic bone disease related to chronic steroid use. The incidence of osteonecrosis can be as high as $9-40 \%$ in patients receiving long-term glucocorticoid therapy that may occur even without steroidinduced osteoporosis $[20,32]$. The disease can occur as early as within 36 days of $16 \mathrm{mg}$ daily dose of oral methylprednisolone with a cumulative dose of $576 \mathrm{mg}$ [32]. Glucocorticoid-induced osteonecrosis is the most common complication of steroid use that receives medi-claim compensations from litigation suits in the US [33].

The pathogenic mechanisms underlying steroid-induced osteonecrosis were thought to be increased bone marrow fat that causes an increased intra-osseous pressure and decreased bone perfusion, fat embolism and hypercoagulability, reducing blood flow to the femoral head, and resultant fatigue fractures [32, 34]. However, recent evidence suggests the role of osteocyte apoptosis in the causation of osteonecrosis [34-36]. Cumulative osteocyte apoptosis over a prolonged period disrupts the normal function of the osteocyte-lacunar-canalicular system of the bone that leads on to a sequence of events resulting in the joint collapse [37].

\section{ICS AND BONE DISEASE}

Although the systemic bioavailability of ICS is claimed to be minimal, they tend to occur in a significant number of ICS users, especially among those who receive large doses. A recent meta-analysis examining the fracture risk in 17513 patients with COPD on ICS, found a $27 \%$ increase in the relative risk of osteoporotic fractures, although a $20-25 \%$ relative reduction of COPD exacerbations benefited the treatment group [38]. Even after adjustments for covariates such as age, body mass index, smoking, self-reported health, alcohol (drinks per week), calcium, PASE (physical activity scale for the elderly) score, coronary artery disease, stroke, and diabetes, the mean annual percentage in the BMD loss in COPD and asthma patients was significantly higher in patients on ICS compared to controls (0.91 [95\% CI: 0.72 1.11 ] vs 0.57 [95\% CI: $0.44-0.70]$; p 0.02) [39]. Men in this cohort study on ICS showed a 2-fold elevated risk of osteoporotic vertebral fractures. ICS use in childhood was also found to be associated with a decrease in BMD of the lumbar spine and the femoral neck (after adjustments for covariates such as age, sex, pubertal stage, height, weight, and use of systemic steroids) at late school age [40].

Osteonecrosis related to ICS use is very uncommon and available data is limited only to case reports [41-44]. Concomitant use of oral steroids for exacerbation of primary lung conditions such as asthma and COPD increases the risk of osteonecrosis from ICS. Corticosteroids are metabolised in the liver by Cytochrome P450 enzyme (mainly CYP3A4) system and the medications that induce this enzyme system may increase the systemic bioavailability of steroids leading to toxicity. Increasing use of anti-retroviral medications such as retonavir, which are powerful CYP3A4 inducers, have been found to be associated with a higher risk of ICS-related osteonecrosis [43, 44].

The systemic bioavailability of ICS differs with the type of steroid molecule, particle size, and mode of inhaler technique used. The systemic toxicity also depends on the pharmaco-kinetic and pharmaco-dynamic properties of the steroid molecule used. Although newer ICS molecules with lower systemic bioavailability such as CIC were shown to have negligible effects on the bone metabolism and turn over [45], there are no head-to head comparative trials examining the potential harmful effects of different ICS agents currently available in the market, on bone health. Therefore, vigilance from medical practitioners is essential for the early identification and management of ICS-related bone disease, and also for preventive strategies.

The adverse consequences of ICS on bone metabolism can retard growth in children with a reduction of effective adult height in chronic users, especially those who are on higher doses. The Childhood Asthma Management Program (CAMP) study showed that BUD at $200 \mu \mathrm{g}$ twice daily administered through a Turbohaler was associated with a lower height after 4-6 years of treatment and slower growth velocity during the first year of treatment compared with Nedocromil sodium $8 \mathrm{mg}$ twice daily or placebo [46]. The follow-up study of the CAMP trial showed that the initial decrease in attained height associated with the use of ICS in pre-pubertal children persisted as a reduction in adult height, although the decrease was not progressive or cumulative [47]. Because of the lack of, or incomplete reporting of growth velocity in the majority of ICS trials in the paediatric age-groups, a recent Cochrane review recommended systematic documentation of growth effects of ICS in all future clinical trials [48].

\section{CLINICAL EVALUATION OF BONE DISEASE RELATED TO ICS USE}

Prompt and early recognition of metabolic bone disease that can complicate long-term use of ICS is of paramount importance because of the adverse health implications of established disease. Patients on moderate to large doses of ICS are particularly vulnerable and require evaluation for adverse metabolic effects on bones. Chronic respiratory illnesses as such can be associated with reductions in the BMD [49]. Repeated use of rescue oral corticosteroids for exacerbations of chronic respiratory disease augments the bone disease related to ICS use. Litigations related to the lack of communication between healthcare professionals and patients on the skeletal complications from corticosteroids are not rare [33], although physicians often ignore the importance of these discussions.

Loss of height may be an early indicator of vertebral compression fractures from osteoporosis and therefore, assessment of height may be helpful for the initial diagnostic work up. Prevalent vertebral fractures are associated with an increased risk of future fractures [20]. A thorough history of previous falls and back pain may be helpful in identifying antecedent trauma that may increase the fracture risk in cases with established osteoporosis. History about the duration of respiratory illness, alcohol intake, smoking status, amount of 
daily exercise, calcium and vitamin $\mathrm{D}$ intake, previous fragility fractures, family history of osteoporotic fractures and menstrual history in females should be obtained. An assessment of the nutritional status and the body mass index (BMI) should be done in all cases.

Assessments of renal function, liver function and levels of calcium, phosphate, parathyroid hormone and vitamin D are useful for the initial laboratory work up. Plain radiographs may be useful to detect established fractures. BMD assessment is useful for established ICS-induced osteopenia and osteoporosis. BMD measurement is insensitive for initial risk assessment because of the mismatch between bone quantity and bone quality in osteoporosis related to steroid use [50]. BMD data can be useful in follow up of cases after the initial intervention. The WHO fracture risk scoring algorithm (FRAX score) has limitations in patients with steroid-induced osteoporosis as it underestimates the risk of fractures in patients on steroids (as the duration and cumulative dose of steroids that substantially increase the fracture risk, are not included in the scoring system) [20].

Although relatively rare when compared to oral or intraarticular steroid use, patients on ICS who report persistent hip, knee, or shoulder pain should be evaluated to rule out the possible occurrence of osteonecrosis as a complication. Established cases demonstrate severe pain on movement of the joint along with tenderness and reduced range of mobility. A subchondral crescent sign may be seen on plain radiographs in the late stages of the disease [32]. Magnetic resonance imaging (MRI) is the investigation of choice for diagnosing these signs [51]. Computed tomography of the affected site or arthroscopy of the joint may be necessary for establishing the diagnosis in patients who are unable to undergo MRI.

There are no formal guidelines for the evaluation and management of bone disease in patients on ICS. However, because of the relatively higher risk of metabolic bone disease in ICS users especially in those on moderate to high doses, and those with severe respiratory illnesses, an evaluation of bone health would seem rational. The osteoporosis risk factor assessment should include: age $>60$ years, BMI $<24 \mathrm{~kg} / \mathrm{M}^{2}$, presence of other systemic diseases (rheumatoid arthritis, polymyalgia rheumatica, inflammatory bowel disease, and post-transplant status), smoking, excessive alcohol consumption, frequent falls, previous fractures, abnormal glucocorticoid genotype, longer duration and higher doses of steroid use, and the family history of hip fracture [3].

The American College of Rheumatology (ACR) published guidelines [52] for the management of Glucocorticoid-induced osteoporosis (GIO) in 2010 and the American Society for Bone and Mineral Research (ASBMR) called for this to be simplified [53]. The initial assessment according to the ACR criteria for GIO considers whether the patient is premenopausal (female) or $\leq 50$ years (male) $\lceil 3\rceil$. If the patient had a previous fragility fracture, this rule does not apply, and requires assessment via a thoracic and lumbar radiograph or a DEXA scan to assess for GIO $[3,54,55]$. In patients $\leq 50$ years, $Z$ scores $\leq-2$ are considered as low BMD [3]. Although these guidelines do not apply to all patients on ICS, they can be utilized for the diagnosis, prevention and management of GIO among ICS users in the high risk categories mentioned above. FRAX risk scoring can be utilized to categorise the risk groups in postmenopausal women and older men [3]. Patients in the high risk group are assessed and managed in the same way as cases of GIO; low and moderate risk groups may not need to be managed at aggressively. There is still uncertainty on the follow up and management of these patients.

\section{MANAGEMENT OF OSTEOPENIA AND OSTEO- POROSIS IN ICS USERS}

\section{Vitamin D and Calcium Supplements}

All patients with established metabolic bone disease should receive vitamin $\mathrm{D}$ and calcium supplements [3, 20, 56] The recommended dose of calcium is $1200 \mathrm{mg}$ per day in divided doses (dietary and supplement) and vitamin $\mathrm{D}$ is 800-2000 units per day [20]. Calcium and vitamin D supplements also reduce the risk of secondary hyperparathyroidism that increases the fracture risk [57]. Appropriate nutrition and physical activities along with calcium and vitamin D are of paramount importance in all patients.

\section{Bisphosphonates}

Bisphosphonates such as alendronate, risedronate, ibadronate and zoledronic acid are the approved agents for first-line treatment of GIO. A 30-60\% reduction of fracture risk with bisphosphonate treatment was evident in multiple clinical trials [58-60]. The mechanism of action is by osteoclast inhibition and potentially by prevention of steroidinduced osteophyte apoptosis [20]. The overall safety profile of bisphosphonates are favourable for regular use. However, concerns on the long-term adverse effects such as atypical subtrochanteric fractures, oesophageal cancer and atrial fibrillation have been raised in several studies, the overall evidence of association of these complications is conflicting and needs further clarification [57]. The risk-benefit ratio currently favours the use of bisphosphonates in the prevention of osteoporotic fractures from GIO. Cumulative toxicity occurs with renal impairment and these drugs should be avoided when glomerular filtration rate falls below 30 $\mathrm{ml} /$ minute [61]. Poor adherence to treatment is an important issue with bisphosphonate treatment and annual supervised intravenous therapy with the long-acting agent zoledronic acid may largely resolve this issue. Table $\mathbf{1}$ shows the bisphosphonates available for clinical use, the dosages and its common side effects.

\section{Teriparatide}

Teriparatide is a recombinant form of human parathyroid hormone that is licensed for the treatment of GIO. The drug is administered in the dose of $20 \mu \mathrm{g} /$ day subcutaneously for two years followed by a bisphosphonate as long as steroid treatment is continued [20]. Teriparatide was found to be superior to alendronate in patients with GIO by its more rapid and favourable effects on BMD with a vertebral fracture risk reduction of $90 \%$ [62]. The need for parenteral administration, higher costs and mild hypercalcemia limits its use in clinical practice. Common side effects are 
Table 1. Different bisphosphonates, the doses and common side effects.

\begin{tabular}{|c|c|c|}
\hline Drug & Dosage & Common Side Effects \\
\hline \hline Alendronate & $10 \mathrm{mg} /$ day or $70 \mathrm{mg} /$ week orally & $\begin{array}{c}\text { Heartburn, dyspepsia, musculo-skeletal pain, oesophagitis and } \\
\text { oesophageal ulceration. Cumulative toxicity in CKD } \geq \text { stage } 4 . \\
\text { Osteonecrosis of jaw can occur with dental procedures }\end{array}$ \\
\hline Risedronate & $5 \mathrm{mg} /$ day or $35 \mathrm{mg} /$ week orally & Similar to alendronate and skin rash and arthralgia \\
\hline Ibadronate & $150 \mathrm{mg} / \mathrm{month}$ orally or $3 \mathrm{mg}$ intravenously every 3 months & $\begin{array}{c}\text { Dyspepsia, hypophosphatemia, Hypo-calcaemia, flu-like symptoms, } \\
\text { oesophagitis }\end{array}$ \\
\hline Zoledronic acid & $5 \mathrm{mg}$ intravenously annually & GI side effects are less common. Flu-like symptoms for up to 3 days \\
of infusion.
\end{tabular}

dyspepsia, hypercalciuria and hypercalcemia [61]. Animal models showed increased risk of osteosarcoma when the drug is administered for more than 2 years and therefore, teriparatide use is limited to 2 years [61]. The drug is also contraindicated in children and growing young adults. The drug is costly and is usually recommended as a second-line agent when bisphosphonates are not tolerated or the response is suboptimal.

\section{Denosumab}

Denosumab is a humanized monoclonal antibody to the RANKL that is useful for the prevention of vertebral, nonvertebral, and hip fractures in postmenopausal women with osteoporosis [63]. The drug inhibits osteoclast formation, function and survival, and therefore reduces bone resorption. The effect of denosumab on osteoporosis related to ICS use is not yet studied in clinical trials. However, when used in patients taking oral steroids for rheumatoid arthritis, significant improvement in BMD in the lumbar spine and femoral necks compared to placebo was observed, regardless of the exposure to glucocorticoids or bisphosphonates [64]. Common side effects include gastrointestinal intolerance, chest and urinary infections, hypocalcemia and hypophosphatemia. Atypical femoral fractures are reported on prolonged use. The usual dose is $60 \mathrm{mg}$ subcutaneously every 6 months. The drug is usually recommended as a second-line agent when bisphosphonates fail or are not tolerated.

\section{Other Pharmacological Agents}

These agents are usually considered for patients who do not tolerate the first-line therapy or when it fails. Strontium renolate stimulates bone formation and reduces bone resorption by augmenting osteoblastogensis and enhancing osteoclast apoptosis [65]. However, because of the adverse cardiovascular effects the drug is used only if the benefits on bone disease outweigh the potential risk. Selective estrogen receptor modulators (SERMs) such as raloxifene, lasofoxifene and bezedoxifene are useful as second-line agents in postmenopausal women with osteoporosis who are unsuitable candidates for the use of bisphosphonate [66]. Newer agents such as romosozumab (a monoclonal antibody against sclerostin that interferes with osteoblast function) are emerging as promising tools in the therapeutic armamentarium against osteoporosis [66, 67].

\section{MANAGEMENT OF OSTEONECROSIS}

The management of osteonecrosis depends on the stage of the disease. About $40 \%$ of early lesions do not progress and avoidance of weight bearing and analgesia would hasten the healing process [32, 68]. For more advanced disease surgical intervention may be necessary. Total hip replacement is the option for severe disease with collapsed femoral head.

Treatment with bisphosphonates may improve the outcome in osteonecrosis. Alendronate has been shown to retard the progression of osteonecrosis significantly in an open-label, randomized, controlled trial [68]. Improvement of pain and ability to weight bear were the other benefits in alendronate treated patients. Sustained improvement of pain and functional regain were demonstrated in the treatment group in another long-term follow up study [32, 69]. The management of osteonecrosis of the jaw related to bisphosphonate use is by analgesia, antibiotics and stopping the bisphosphonate [70].

\section{SUMMARY AND RECOMMENDATIONS FOR ICS- INDUCED BONE DISEASE}

There are no formal recommendations from professional bodies on the management of ICS-induced bone disease, because of the lack adequate evidence based on large clinical trials. However, few small studies showed clear benefit favouring the use of bisphosphonates especially in high risk individuals on ICS treatment [71-74]. The risk of osteopenia and osteoporosis is negligible in patients receiving low to moderate dose ICS treatment, especially in the absence of co-existent conditions that increase risk of developing metabolic bone disease. Those receiving high dose ICS with intermittent rescue steroids by systemic route are particularly vulnerable to developing ICS-induced bone disease. Therefore, a proper risk assessment should help clinicians in planning appropriate treatment options for high risk individuals.

The ACR recommendations on management of GIO can be applied to high risk patients on ICS treatment. The FRAX tool can be used to calculate the risk, although this scoring system is not applicable to premenopausal women and men aged $<50$ years [66]. An algorithm for the evaluation and management of bone disease in ICS users is shown in the Fig. (1). Clinicians should monitor patients on bisphosphonates for the possible complication of atypical femoral 


\section{Chronic Inhalational Corticosteroid (ICS) user}

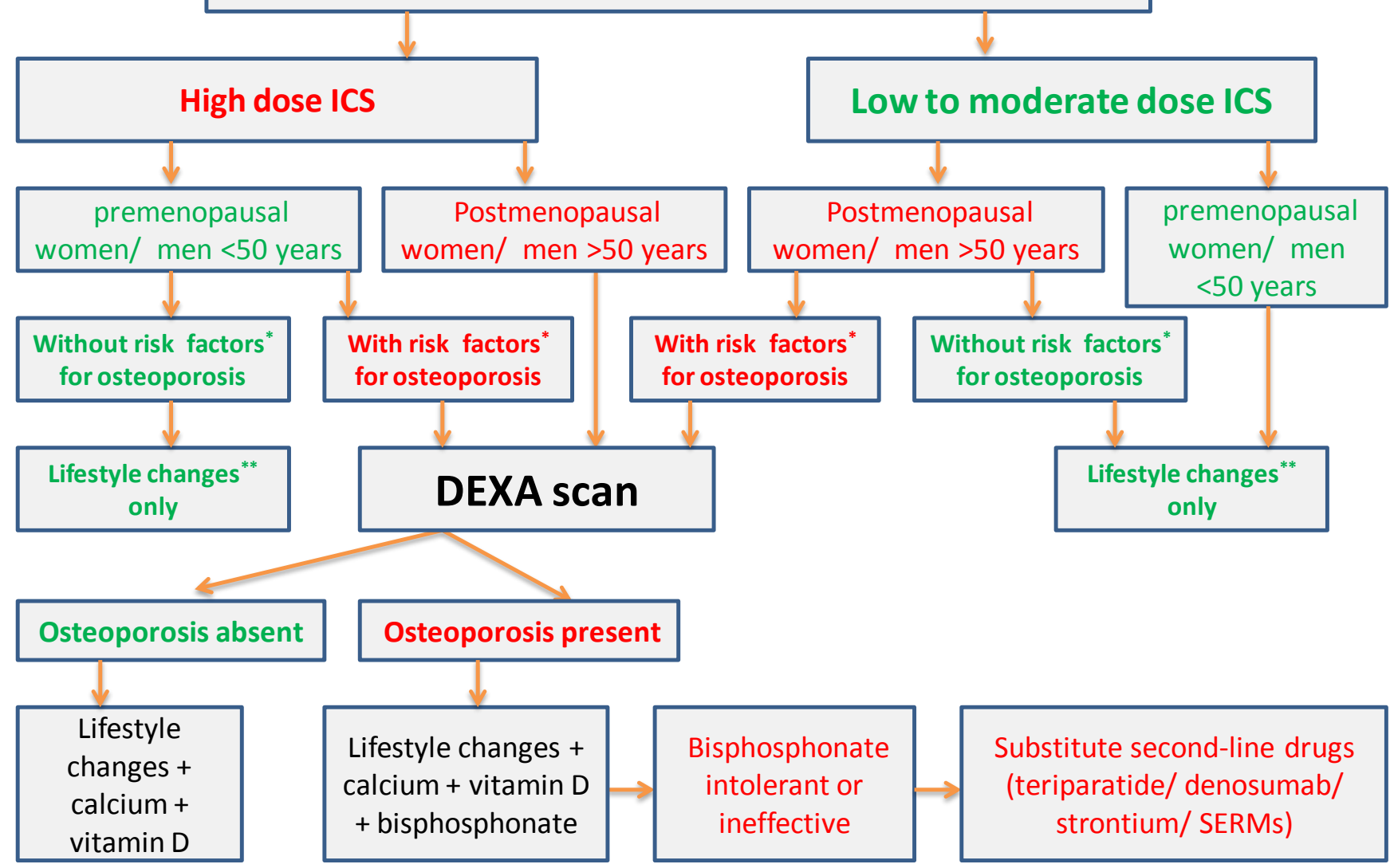

Fig. (1). The algorithm for the evaluation and management of bone disease in inhalational corticosteroid (ICS) users. Risk factors ${ }^{*}$ for osteoporosis are mentioned in the main text of the article. Lifestyle changes ${ }^{* *}$ include regular exercises and good nutrition. SERMs selective estrogen receptor modulators.

fractures. Osteonecrosis of the long bones should be managed with analgesia, avoidance of weight bearing, bisphosphonates, and when severe, surgical intervention.

\section{CONFLICT OF INTEREST}

The authors confirm that this article content has no conflict of interest.

\section{ACKNOWLEDGEMENTS}

None declared.

\section{REFERENCES}

[1] Raissy HH, Kelly HW, Harkins M, Szefler SJ. Inhaled corticosteroids in lung diseases. Am J Respir Crit Care Med 2013; 187: 798-803

[2] Kelly HW. Potential adverse effects of inhaled corticosteroids. $J$ Allergy Clin Immunol 2003; 112: 469-78.

[3] Buehring B, Viswanathan R, Binkley N, Busse W. Glucocorticoidinduced osteoporosis: an update on effects and management. J Allergy Clin Immunol 2013; 132: 1019-30.

[4] Bonewald LF. The amazing osteocyte. J Bone Miner Res 2011; 26: 229-38.

[5] McCormick RK. Osteoporosis: integrating biomarkers and other diagnostic correlates into the management of bone fragility. Altern Med Rev 2007; 12: 113-45.
[6] Rachner TD, Khosla S, Hofbauer LC. Osteoporosis: now and the future. Lancet 2011; 377(9773): 1276-87.

[7] Kobayashi K, Takahashi N, Jimi E, et al. Tumor necrosis factor alpha stimulates osteoclast differentiation by a mechanism independent of the ODF/RANKL-RANK interaction. J Exp Med 2000; 191: 275-86.

[8] Zhao R. Immune regulation of osteoclast function in postmenopausal osteoporosis: a critical interdisciplinary perspective. Int J Med Sci 2012; 9: 825-32.

[9] Weinstein RS, Jilka RL, Parfitt AM, et al. Inhibition of osteoblastogenesis and promotion of apoptosis of osteoblasts and osteocytes by glucocorticoids: potential mechanisms of the deleterious effects on bone. J Clin Invest 1998; 102: 274-82.

[10] Weinstein RS. Glucocorticoid-induced osteoporosis and osteonecrosis. Endocrinol Metab Clin North Am 2012; 41: 595611.

[11] Wang FS, Ko JY, Yeh DW, Ke HC, Wu HL. Modulation of Dickkopf-1 attenuates glucocorticoid induction of osteoblast apoptosis, adipocytic differentiation, and bone mass loss. Endocrinology 2008; 149: 1793-801.

[12] Georgiou KR, Hui SK, Xian CJ. Regulatory pathways associated with bone loss and bone marrow adiposity caused by aging, chemotherapy, glucocorticoid therapy and radiotherapy. Am J Stem Cells 2012; 1: 205-24.

[13] Almeida M, Han L, Ambrogini E, Weinstein RS, Manolagas SC. Glucocorticoids and tumor necrosis factor $\alpha$ increase oxidative stress and suppress Wnt protein signaling in osteoblasts. J Biol Chem 2011; 286: 44326-35.

[14] Rauch A, Seitz S, Baschant U, et al. Glucocorticoids suppress bone formation by attenuating osteoblast differentiation via the monomeric glucocorticoid receptor. Cell Metab 2010; 11: 517-31. 
[15] Kim HJ, Zhao H, Kitaura H, et al. Glucocorticoids suppress bone formation via the osteoclast. J Clin Invest 2006; 116: 2152-60.

[16] Lane NE, Yao W, Balooch M, et al. Glucocorticoid-treated mice have localized changes in trabecular bone material properties and osteocyte lacunar size that are not observed in placebo-treated or estrogen-deficient mice. J Bone Min Res 2006; 21: 466-76.

[17] Xia X, Kar R, Gluhak-Heinrich J, et al. Glucocorticoid-induced autophagy in osteocytes. J Bone Miner Res 2010; 25: 2479-88.

[18] Bollet AJ, Black R, Bumin JJ. Major undesirable side-effects resulting from prednisolone and prednisone. JAMA 1955; 157: 459-63.

[19] Heiman WG, Freiberger RH. Avascular necrosis of the femoral and humeral heads after high-dosage corticosteroid therapy. N Engl J Med 1960; 263: 672-5.

[20] Weinstein RS. Glucocorticoid-induced bone disease. N Engl J Med 2011; 365: 62-70.

[21] Khan N, Abbas AM, Almukhtar RM, Khan A. Prevalence and predictors of low bone mineral density in males with ulcerative colitis. J Clin Endocrinol Metab 2013; 98: 2368-75.

[22] LoCascio V, Bonucci E, Imbimbo B, et al. Bone loss in response to long-term glucocorticoid therapy. Bone Miner 1990; 8: 39-51.

[23] van Staa TP, Laan RF, Barton IP, et al. Bone density threshold and other predictors of vertebral fracture in patients receiving oral glucocorticoid therapy. Arth Rheum 2003; 48: 3224-29.

[24] O'Brien CA, Jia D, Plotkin LI, et al. Glucocorticoids act directly on osteoblasts and osteocytes to induce their apoptosis and reduce bone formation and strength. Endocrinology 2004; 145: 1835-41.

[25] Canalis E, Mazziotti G, Giustina A, Bilezikian JP. Glucocorticoidinduced osteoporosis: pathophysiology and therapy. Osteoporos Int 2007; 18: 1319-28.

[26] Weinstein RS, Wan C, Liu Q, et al. Endogenous glucocorticoids decrease skeletal angiogenesis, vascularity, hydration, and strength in aged mice. Aging Cell 2010; 9: 147-61

[27] Gordon CM, Bachrach LK, Carpenter TO, et al. Dual energy X-ray absorptiometry interpretation and reporting in children and adolescents: the 2007 ISCD Pediatric Official Positions. J Clin Densitom 2008; 11: 43-58.

[28] Levis S, Theodore G. Summary of AHRQ's comparative effectiveness review of treatment to prevent fractures in men and women with low bone density or osteoporosis: update of the 2007 report. J Manag Care Pharm 2012; 18(4 Suppl B): S1-15.

[29] Gonnelli S, Caffarelli C, Nuti R. Obesity and fracture risk. Clin Cases Miner Bone Metab 2014; 11: 9-14.

[30] Klop C, Welsing PM, Cooper C, et al. Mortality in British hip fracture patients, 2000-2010: A population-based retrospective cohort study. Bone 2014; 66: 171-77.

[31] Canalis E, Mazziotti G, Giustina A, Bilezikian JP. Glucocorticoidinduced osteoporosis: pathophysiology and therapy. Osteoporos Int 2007; 18: 1319-28.

[32] Weinstein RS. Glucocorticoid-induced osteonecrosis. Endocrine 2012; 41: 183-90.

[33] Nash JJ, Nash AG, Leach ME, Poetker DM. Medical malpractice and corticosteroid use. Otolaryngol Head Neck Surg 2011; 144: 1015.

[34] Drescher W, Schlieper G, Floege J, Eitner F. Steroid-related osteonecrosis-an update. Nephrol Dial Transplant 2010; 26: 172831.

[35] Ko JY, Wang FS, Wang CJ, Wong T, Chou WY, Tseng SL. Increased Dickkopf-1 expression accelerates bone cell apoptosis in femoral head osteonecrosis. Bone 2010; 46: 584-91.

[36] Youm YS, Lee SY, Lee SH. Apoptosis in the osteonecrosis of the femoral head. Clin Orthop Surg 2010; 2: 250-55.

[37] Weinstein RS, Nicholas RW, Manolagas SC. Apoptosis of osteocytes in glucocorticoid-induced osteonecrosis of the hip. Endocrinology 2000; 85: 2907-12.

[38] Loke YK, Cavallazzi R, Singh S. Risk of fractures with inhaled corticosteroids in COPD: systematic review and meta-analysis of randomised controlled trials and observational studies. Thorax 2011; 66: 699-708.

[39] Dam TT, Harrison S, Fink HA, Ramsdell J, Barrett-Connor E; Osteoporotic Fractures in Men (MrOS) Research Group. Bone mineral density and fractures in older men with chronic obstructive pulmonary disease or asthma. Osteoporos Int 2010; 21: 1341-49.

[40] Sidoroff VH, Ylinen MK, Kröger LM, Kröger HP, Korppi MO. Inhaled corticosteroids and bone mineral density at school age: a follow-up study after early childhood wheezing. Pediatr Pulmonol 2013 Dec 17. doi: 10.1002/ppul.22968. [Epub ahead of print].

[41] Kisielinski K, Niedhart C, Schneider U, Niethard FU. Osteonecrosis 15 years after femoral neck fracture and long-term low-dose inhaled corticosteroid therapy. Joint Bone Spine 2004; 71: 237-39.

[42] Drigo I, Saccari A, Barbi E, Bartoli F, Decorti G, Ventura A. Osteonecrosis of the hip after short courses of oral and inhaled steroids in a child with an increased number of glucocorticoid receptors. Eur J Pediatr 2006; 165: 913-15.

[43] Kaviani N, Bukberg P, Manessis A, Yen V, Young I. Iatrogenic osteoporosis, bilateral HIP osteonecrosis, and secondary adrenal suppression in an HIV-infected man receiving inhaled corticosteroids and ritonavir-boosted highly active antiretroviral therapy. Endocr Pract 2011; 17: 74-78.

[44] Pollett S, Graves B, Richards B, MacLeod C. Avascular necrosis in a HIV patient receiving ritonavir and inhaled fluticasone. Int J STD AIDS 2014; 25: 458-60.

[45] Anderson WJ, McFarlane LC, Lipworth BJ. Prospective follow-up of novel markers of bone turnover in persistent asthmatics exposed to low and high doses of inhaled ciclesonide over 12 months. J Clin Endocrinol Metab 2012; 97: 1929-36.

[46] Szefler S, Weiss S, and Tonascia J. Long-term effects of budesonide or nedocromil in children with asthma. The Childhood Asthma Management Program Research Group. N Engl J Med 2000; 343: 1054-63.

[47] Kelly HW, Sternberg AL, Lescher R, et al. Effect of inhaled glucocorticoids in childhood on adult height. N Engl J Med 2012; 367: 904-12.

[48] Pruteanu AI, Chauhan BF, Zhang L, Prietsch SO, Ducharme FM. Inhaled corticosteroids in children with persistent asthma: doseresponse effects on growth. Cochrane Database Syst Rev 2014; 7: CD009878.

[49] Xiaomei W, Hang X, Lingling L, Xuejun L. Bone Metabolism Status and Associated Risk Factors in Elderly Patients with Chronic Obstructive Pulmonary Disease (COPD). Cell Biochem Biophys 2014; 70: 129-34.

[50] Angeli A, Guglielmi G, Dovio A, et al. High prevalence of asymptomatic vertebral fractures in post-menopausal women receiving chronic glucocorticoid therapy: a cross-sectional outpatient study. Bone 2006; 39: 253-59.

[51] Zalavras CG, Lieberman JR. Osteonecrosis of the femoral head: evaluation and treatment. J Am Acad Orthop Surg 2014; 22: 45564.

[52] Grossman JM, Gordon R, Ranganath VK, et al. American College of Rheumatology 2010 recommendations for the prevention and treatment of glucocorticoid-induced osteoporosis. Arthritis Care Res (Hoboken) 2010; 62: 1515-26.

[53] Hansen KE, Wilson HA, Zapalowski C, Fink HA, Minisola S, Adler RA. Uncertainties in the prevention and treatment of glucocorticoid-induced osteoporosis. J Bone Miner Res 2011; 26: 1989-96.

[54] Fuerst T, Wu C, Genant HK, et al. Evaluation of vertebral fracture assessment by dual X-ray absorptiometry in a multicenter setting. Osteoporos Int 2009; 20: 1199-205.

[55] Schousboe JT, Vokes T, Broy SB, et al. Vertebral Fracture Assessment: the 2007 ISCD Official Positions. J Clin Densitom 2008; 11: 92-108.

[56] Mazzantini M, Di Munno O. Glucocorticoid-induced osteoporosis: 2013 update. Reumatism 2014; 66(2): 144-52.

[57] Kanis JA, McCloskey EV, Johansson H, Cooper C, Rizzoli R, Reginster JY; Scientific Advisory Board of the European Society for Clinical and Economic Aspects of Osteoporosis and Osteoarthritis (ESCEO) and the Committee of Scientific Advisors of the International Osteoporosis Foundation (IOF). European guidance for the diagnosis and management of osteoporosis in postmenopausal women. Osteoporos Int 2013; 24: 23-57.

[58] Stevenson M, Jones ML, De Nigris E, Brewer N, Davis S, Oakley J. A systematic review and economic evaluation of alendronate, etidronate, risedronate, raloxifene and teriparatide for the prevention and treatment of postmenopausal osteoporosis. Health Technol Assess 2005; 9: 1-160.

[59] Cranney A, Guyatt G, Griffith L, Wells G, Tugwell P, Rosen C. Meta-analyses of therapies for postmenopausal osteoporosis. IX summary of meta-analyses of therapies for postmenopausal osteoporosis. Endocr Rev 2002; 23: 570-78. 
[60] Harris ST, Blumentals WA, Miller PD. Ibandronate and the risk of non-vertebral and clinical fractures in women with postmenopausal osteoporosis: results of a meta-analysis of phase III studies. Curr Med Res Opin 2008; 24: 237-45.

[61] McGreevy C, Williams D. Safety of drugs used in the treatment of osteoporosis. Ther Adv Drug Saf 2011; 2: 159-72.

[62] Saag KG, Shane E, Boonen S, et al. Teriparatide or alendronate in glucocorticoid-induced osteoporosis. N Engl J Med 2007; 357: 2028-39.

[63] Cummings SR, San Martin J, McClung MR, et al. Denosumab for prevention of fractures in postmenopausal women with osteoporosis. N Engl J Med 2009; 361: 756-65 [Erratum, N Engl J Med 2009; 361: 1914

[64] Dore RK, Cohen SB, Lane NE, et al. Effects of denosumab on bone mineral density and bone turnover in patients with rheumatoid arthritis receiving concurrent glucocorticoids or bisphosphonates. Ann Rheum Dis 2010; 69: 872-75.

[65] Nardone V, D'Asta F, Brandi ML. Pharmacological management of osteogenesis. Clinics (Sao Paulo) 2014; 69: 438-46.

[66] Aljubran SA, Whelan GJ, Glaum MC, Lockey RF. Osteoporosis in the at-risk asthmatic. Allergy 2014 Jul 21. doi: 10.1111/all.12438. [Epub ahead of print].

[67] McClung MR, Grauer A, Boonen S. Romosozumab in postmenopausal women with low bone mineral density. N Engl J Med 2014; 370: 412-20.

[68] Lai KA, Shen WJ, Yang CY, Shao CJ, Hsu JT, Lin RM. The use of alendronate to prevent early collapse of the femoral head in patients with nontraumatic osteonecrosis. J Bone Jt Surg Am 2005; 87: 2155-59.

[69] Agarwala S, Shah SB. Ten-year follow-up of avascular necrosis of femoral head treated with alendronate for 3 years. J Arthroplast 2011; 26: 1128-34.

[70] Sigua-Rodriguez EA, da Costa Ribeiro R, de Brito AC, AlvarezPinzon N, de Albergaria-Barbosa JR. Bisphosphonate-related osteonecrosis of the jaw: a review of the literature. Int J Dent 2014; 2014: 192320.

[71] Lau EM, Woo J, Chan YH, Li M. Alendronate for the prevention of bone loss in patients on inhaled steroid therapy. Bone 2001; 29: 506-10.

[72] Herrala J, Puolijoki H, Liippo K, Raitio M, Impivaara O, Tala E, Nieminen MM. Clodronate is effective in preventing corticosteroid-induced bone loss among asthmatic patients. Bone 1998; 22: 577-82.

[73] Campbell IA, Douglas JG, Francis RM, Prescott RJ, Reid DM; Research Committee of the British Thoracic Society. Five year study of etidronate and/or calcium as prevention and treatment for osteoporosis and fractures in patients with asthma receiving long term oral and/or inhaled glucocorticoids. Thorax 2004; 59: 761-68.

[74] Kasayama S, Fujita M, Goya K, Yamamoto H, Fujita K, Morimoto Y, Kawase I, Miyatake A. Effects of alendronate on bone mineral density and bone metabolic markers in postmenopausal asthmatic women treated with inhaled corticosteroids. Metabolism 2005; 54: 85-90.

(C) Chee et al.; Licensee Bentham Open.

This is an open access article licensed under the terms of the Creative Commons Attribution Non-Commercial License (http://creativecommons.org/licenses/by-nc/3.0/) which permits unrestricted, non-commercial use, distribution and reproduction in any medium, provided the work is properly cited. 